This article was downloaded by: [130.159.82.179] On: 28 October 2013, At: 07:55

Publisher: Institute for Operations Research and the Management Sciences (INFORMS)

INFORMS is located in Maryland, USA

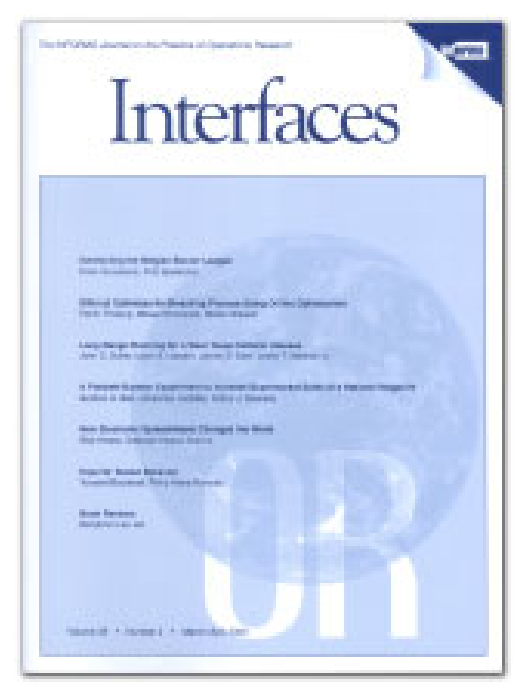

\title{
Interfaces
}

Publication details, including instructions for authors and subscription information:

http:// pubsonline.informs. org

\section{The National Audit Office Uses OR to Assess the Value for Money of Public Services}

Elena Bechberger, David C. Lane, Tom McBride, Alec Morton, Diogo Quintas, Chin Hei Wong,

\section{To cite this article:}

Elena Bechberger, David C. Lane, Tom McBride, Alec Morton, Diogo Quintas, Chin Hei Wong, (2011) The National Audit Office Uses OR to Assess the Value for Money of Public Services. Interfaces 41(4):365-374. http:// dx. doi.org/ 10.1287/ inte.1110.0551

\section{Full terms and conditions of use: http://pubsonline.informs.org/page/terms-and-conditions}

This article may be used only for the purposes of research, teaching, and/or private study. Commercial use or systematic downloading (by robots or other automatic processes) is prohibited without explicit Publisher approval. For more information, contact permissions@informs.org.

The Publisher does not warrant or guarantee the article's accuracy, completeness, merchantability, fitness for a particular purpose, or non-infringement. Descriptions of, or references to, products or publications, or inclusion of an advertisement in this article, neither constitutes nor implies a guarantee, endorsement, or support of claims made of that product, publication, or service.

\section{Copyright (c) 2011, INFORMS}

\section{Please scroll down for article-it is on subsequent pages}

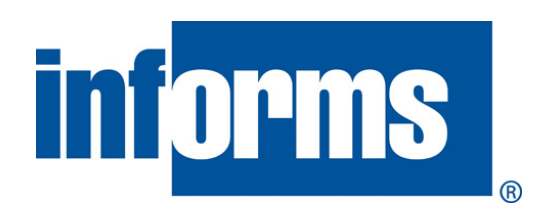

INFORMS is the largest professional society in the world for professionals in the fields of operations research, management science, and analytics.

For more information on INFORMS, its publications, membership, or meetings visit http:// www. informs. org 


\title{
The National Audit Office Uses OR to Assess the Value for Money of Public Services
}

\author{
Elena Bechberger \\ National Audit Office, London SW1W 9SS, United Kingdom, elena.bechberger@nao.gsi.gov.uk \\ David C. Lane \\ Management Science Group and Managerial Economics and Strategy Group, Department of Management, \\ London School of Economics and Political Science, London WC2A 2AE, United Kingdom, d.c.lane@lse.ac.uk \\ Tom McBride \\ National Audit Office, London SW1W 9SS, United Kingdom, tom.mcbride@nao.gsi.gov.uk \\ Alec Morton \\ Management Science Group, Department of Management, London School of Economics and Political Science, \\ London WC2A 2AE, United Kingdom, a.morton@lse.ac.uk \\ Diogo Quintas \\ Centre for Telecommunications Research, King's College London, London WC2R 2LS, United Kingdom, \\ diogo.quintas@kcl.ac.uk

\section{Chin Hei Wong} \\ Management Science Group, Department of Management, London School of Economics and Political Science, \\ London WC2A 2AE, United Kingdom, chinhei@gmail.com
}

\begin{abstract}
Supreme audit institutions (SAIs) have an important role in assessing value for money in the delivery of public services. Assessing value for money necessarily involves assessing counterfactuals: good value for money has been achieved if a policy could not reasonably have been delivered more efficiently, effectively, or economically. Operations research modelling has the potential to help in the assessment of these counterfactuals. However, is such modelling too arcane, complex, and technically burdensome for organisations that, like SAIs, operate in a time- and resource-constrained and politically charged environment? We report on three applications of modelling at the UK's SAI, the National Audit Office, in the context of studies on demand management in tax collection, end-of-life care, and health-care associated infections. In all cases, the models have featured in the audit reports and helped study teams come to a value-for-money judgment. We conclude that OR modelling is indeed a valuable addition to the value-for-money auditor's methodological tool box.
\end{abstract}

Key words: accounting; hospitals: health care, services; government: agencies, tax policy.

History: This paper was refereed.

$\mathrm{T}$ his paper addresses the application of operations research (OR) models in the context of a supreme audit institution (SAI). SAIs, such as the Government Accountability Office (GAO) in the United States and the National Audit Office (NAO) in the UK, are institutions with a distinctive role. They act as independent auditors of public sector accounts; in this sense, they are similar to private sector auditors in the private sector. However, many also have a broader scrutiny role, reporting to the legislature on public sector performance and value for money, and a developmental role, distilling and fostering good practice in public sector management. The latter two roles are sometimes referred to as "value for money" (VFM) audit (or "performance" audit), as opposed to traditional "financial" audit (Barzelay 1997, Pollitt et al. 1999).

With the expansion of the SAI role to include VFM audit, the auditors' toolbox has also grown (Ling 2007). Thus, VFM audit studies use a range of qualitative and quantitative methods, including surveys, focus groups, and statistical analysis of routinely collected data. These methods sit alongside traditional audit tools, such as document reviews and client 
interviews. However, one tool that SAIs have been slow to adopt is OR modelling. For example, in a review of methods used by SAIs, Pollitt et al. (1999, Chapter 8) find four reports that use "modelling" in a sample of 578 reports during the 1980s and 1990s.

The UK's SAI, the National Audit Office (NAO), has in the past few years developed an interest in OR techniques, and has used simulation methods (Comptroller and Auditor General 2004) and multicriteria decision analysis (Comptroller and Auditor General 2006) in its audit work. This paper outlines some of the NAO's recent experiences with OR modelling, and reflects on its appropriateness and utility in VFM audits.

\section{Nature of Value for Money Audit}

As of 2009, the NAO had a budget of $£ 76$ million and a staff of 900. Financial audits make up approximately 70 percent of the NAO's work, with VFM audits making up the majority of the remainder. The NAO maintains a framework agreement with a range of consultants with the necessary skills and expertise to support the full range of their financial and VFM audits. This framework is periodically updated, and the NAO is free to use other suppliers if other skills are required or framework members do not have sufficient capacity to support the NAO's work.

Under the terms of the 1983 National Audit Act, the Comptroller and Auditor General (C\&AG), as head of the NAO, has rights of access to assess the efficiency, effectiveness, and economy by which any central government policy is implemented. However, the C\&AG may not question the merits of policy. The NAO produces approximately 60 VFM reports per year (available at http://www.nao.org.uk/), which are the basis for hearings of the Committee of Public Accounts (PAC), a cross-party committee of the UK Parliament. PAC hearings are listed at http://www.parliament .uk/parliamentary_committees/committee_of_public _accounts/pachist.cfm.

PAC, a particularly powerful committee, typically calls accounting officers (i.e., permanent secretaries of government departments or chief executives of agencies) as witnesses to account for the findings of a VFM report. The committee has a reputation for giving brutally frank assessments of managerial competency and performance, which attract considerable press attention. Thus, an adverse NAO report and a poor performance at PAC can be a personally damaging experience for a senior civil servant. Following a hearing, PAC produces a report based on its inquiries and the VFM report; the government must officially respond to the findings.

VFM reports typically take about a year to produce. During the 2008-2009 financial year, NAO reported on issues as diverse and politically sensitive as teaching mathematics in primary schools, antiair warfare capability, and the nationalisation of the Northern Rock bank (Comptroller and Auditor General 2008, 2009c, d).

Although similar in some respects to academic studies, internal corporate research, and consultancy reports, VFM reports differ from each of these on key dimensions, as the following examples illustrate.

- VFM reports have to call poor performance where they see it, whereas academic studies often have greater latitude and can choose to focus on other aspects of the service under question, for example, instances of good practice. (This does not necessarily arise from timidity on the part of academics; without audit rights requiring audited organisations to hand over documentation, pinpointing bad practice can be very difficult.)

- Unlike studies conducted by internal corporate groups, NAO auditors are outsiders to the audited organisation. Although NAO is organised around client groups and invests considerable effort in maintaining relationships with departments, auditors inevitably have less detailed inside knowledge about business processes and data than insiders have. Moreover, because the NAO's role is to provide an outside view, auditors rarely co-opt internal expertise onto the study team; therefore, the learning curve is very steep.

- Unlike consulting studies, VFM reports are placed in the public domain. and they are not addressed to a customer within the organisation but to PAC. As a result, a danger exists that the relationship between the NAO and the client organisation might become adversarial as results and conclusions are challenged prior to publication.

Given sufficient resources, it may be relatively straightforward to establish what has happened as a result of a government policy or intervention; however, to reach a conclusion on whether VFM has been 
achieved, auditors must deal with counterfactuals. They must make ex post comparisons of what did occur (in terms of inputs, outputs, and outcomes), and what would have occurred had different decisions been made or different options been pursued. Thus, in an ex post audit of policy delivery, good VFM has been achieved if a policy could not reasonably have been delivered more efficiently, effectively, or economically (as mandated in the 1983 Audit Act). (A different definition of VFM is used in ex ante appraisals: in such contexts, it is common to apply some sort of "value for money" threshold, requiring a certain minimal rate of return before investment can proceed.)

However, VFM auditors often face challenges in clearly defining and quantifying counterfactuals. Therefore, OR models seem to offer a useful tool for assessing VFM by helping to define and test the likely results of counterfactual scenarios. Because VFM reports also contain recommendations on how to improve service delivery in the future, OR models also have a potential role in assessing the likely effects of these recommendations. However, producing models requires data and technical expertise, and can be a time-consuming and resource-intensive process. It may also produce a range of plausible answers that can be difficult to interpret and challenging to present to a lay reader.

A critical question for SAIs, therefore, is whether modelling methods have anything to offer in this highly political, time-, resource-, and informationconstrained environment, or whether they are an expensive luxury. A further concern is that modelling methods may unnecessarily complicate the process of "clearing" (i.e., agreeing to the factual correctness of evidence and findings between the audited department and the SAI, which is a prerequisite for the publication of VFM reports). In this paper, we describe three modelling experiences undertaken in the context of NAO studies in the areas of tax collection and health care, and reflect on their benefits.

\section{Case Studies}

\section{Demand Management at Her Majesty's Revenue and Customs}

In 2007-2008, HM Revenue \& Customs (HMRC) collected $£ 155$ billion of tax revenue through incometax self-assessment (SA) and pay-as-you-earn (PAYE), which is collected from the taxpayer's salary by the employer. Collecting this revenue required 15,000 staff, 17 percent of the department's workforce. The department aims to meet its efficiency target by reducing its expenditures and the size of its workforce by March 2011, while delivering the same workload.

NAO's preliminary research suggested that there was significant variation in HMRC's workload; for example, in 2006-2007, over one million income tax self-assessment (SA) returns were filed during the January peak period and approximately 759,000 were filed in September; the monthly average was about 684,000 . These variations could have consequences for the department, such as staff overtime requirements, reduced staff performance, work backlogs, work-processing inaccuracy, and inefficient use of resources. Figure 1 shows a high-level map of the work process.

To examine the extent to which this workload variation can affect the efficiency and effectiveness of processing SA returns, while exploring the limitations of the process and better resource deployment to meet the varying demand, author Wong built a discreteevent simulation (DES) model (Banks et al. 2000, Law and Kelton 2000, Pidd 2004) under the supervision of author Morton. The purpose was to simulate the resource utilisation at different stages in the processing of SA returns at an office level, and to conduct "what-if" analyses to understand the behaviour of the system at peak and nonpeak times. The model represented the flow of a case through the postroom where the returns are received, a cleansing and checking stage, data capture, coding, and batching and filing, with processing dependent on the availability of limited staff resources. We also modelled some special cases in which returns must be sent back to taxpayers or require extra processing. The models had two inputs: (1) weekly and monthly resources (measured in staff numbers) available at the office for returns processing, and (2) weekly and monthly volume of tax returns received. The time that each return spends at each workstation was based on data that the department provided.

Two grades of staff are primarily involved in processing SA returns: the junior-level administrative assistant grade (AA) and the senior-level administrative officer grade (AO). The capture process has differing uses of the AA grade (i.e., to log and capture all 


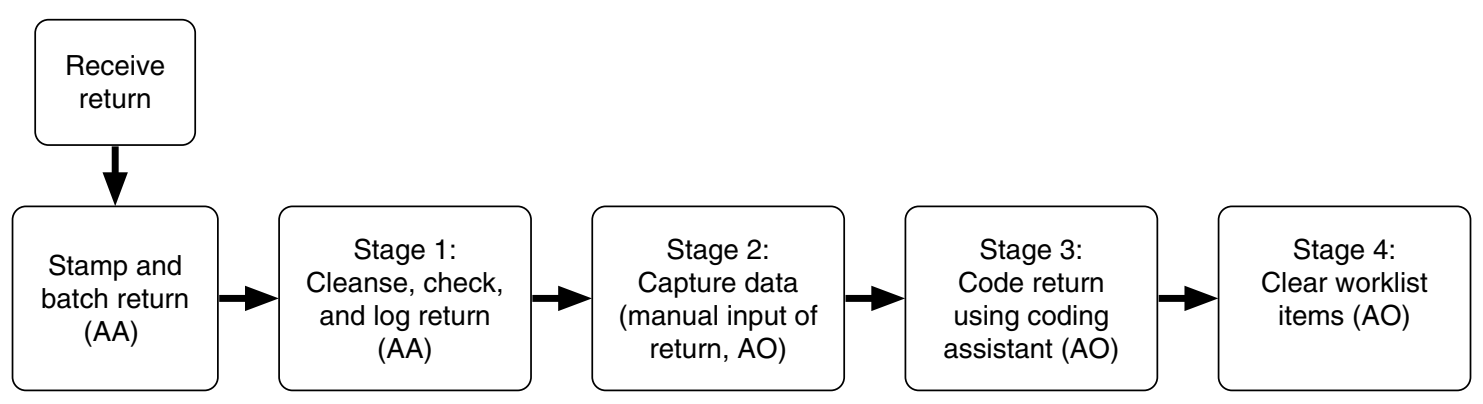

Figure 1: The flowchart illustrates the processing of paper SA returns.

returns with no PAYE element or to capture, to a certain stage, returns with a PAYE element), depending on the availability of AA resources and the product mix of returns. Two offices participated in this study; because the process varied slightly both from office to office and at peak times, we built a separate DES model for each office. We obtained data on weekly workload and resource availability at the individual participating office level, and estimated the cost and time required for each process based on the information provided by the local staff and management.

Figure 2 shows the type of output that the model provided; this illustrates the type of analysis the simulation model was able to undertake and the potential opportunities for improving staff deployment it was able to identify. These charts show system performance under two operating regimes, and display how staff utilisation for the two staff types and backlog vary over time. Under both operating regimes, there is a mismatch of supply and demand in the middle of the year; under regime $\mathrm{B}$ a backlog builds up; under regime A demand is initially absorbed, although a backlog does arise later in the year.

The VFM report (Comptroller and Auditor General 2009b, p. 20) describes the insights this model provided:

We used simulation modelling to identify opportunities for improving staff deployment. Our analysis of work at the two offices suggests that there are opportunities to release resources by getting the right mix of staff and stockpiling returns for some periods. Online filing should allow more even use of staff which would release resources to reduce stockpiles of work and improve customer service. In 2008-09 the Department established separate deadlines for filing paper and electronic tax returns. It now aims to clear 99 per cent of paper returns by 9 January, ahead of the peak in online filing. Our simulation model estimates that this change will lead to a more consistent use of staff over time, and that it could reduce the size of the Self Assessment backlogs generated in year.

The observation that introducing different filing deadlines for paper and online filing has had significant efficiency benefits for the department forms a key element of the VFM conclusion of the NAO report. As a result of its study on workload variations, including the simulation, the NAO concluded that the HMRC's methods of managing variations in workload were "generally consistent with approaches adopted by other organisations" (Comptroller and Auditor General 2009b, p. 6), but that there was nevertheless scope for the further efficiency improvements through the use of automation, and the further development of online services. The department's ability to move staff between activities was limited by its information technology (IT) systems and the additional training that staff would require. Opportunities to make greater use of flexible contracting arrangements were also available (Comptroller and Auditor General 2009b).

\section{End-of-Life Care}

Faced with a terminal illness such as cancer, pulmonary disease, heart failure, or dementia, most people would prefer to die at home and avoid dying in hospital. However, official statistics show that in 2006, 58 percent of deaths in England occurred in a hospital, 35 percent occurred at home or in a care home, and 4 percent occurred in a hospice; the remainder of the deaths were in other places (e.g., prison, car accidents). In addition, many palliative care experts believe that reducing reliance on hospital care and allowing more people to be cared for and die in 

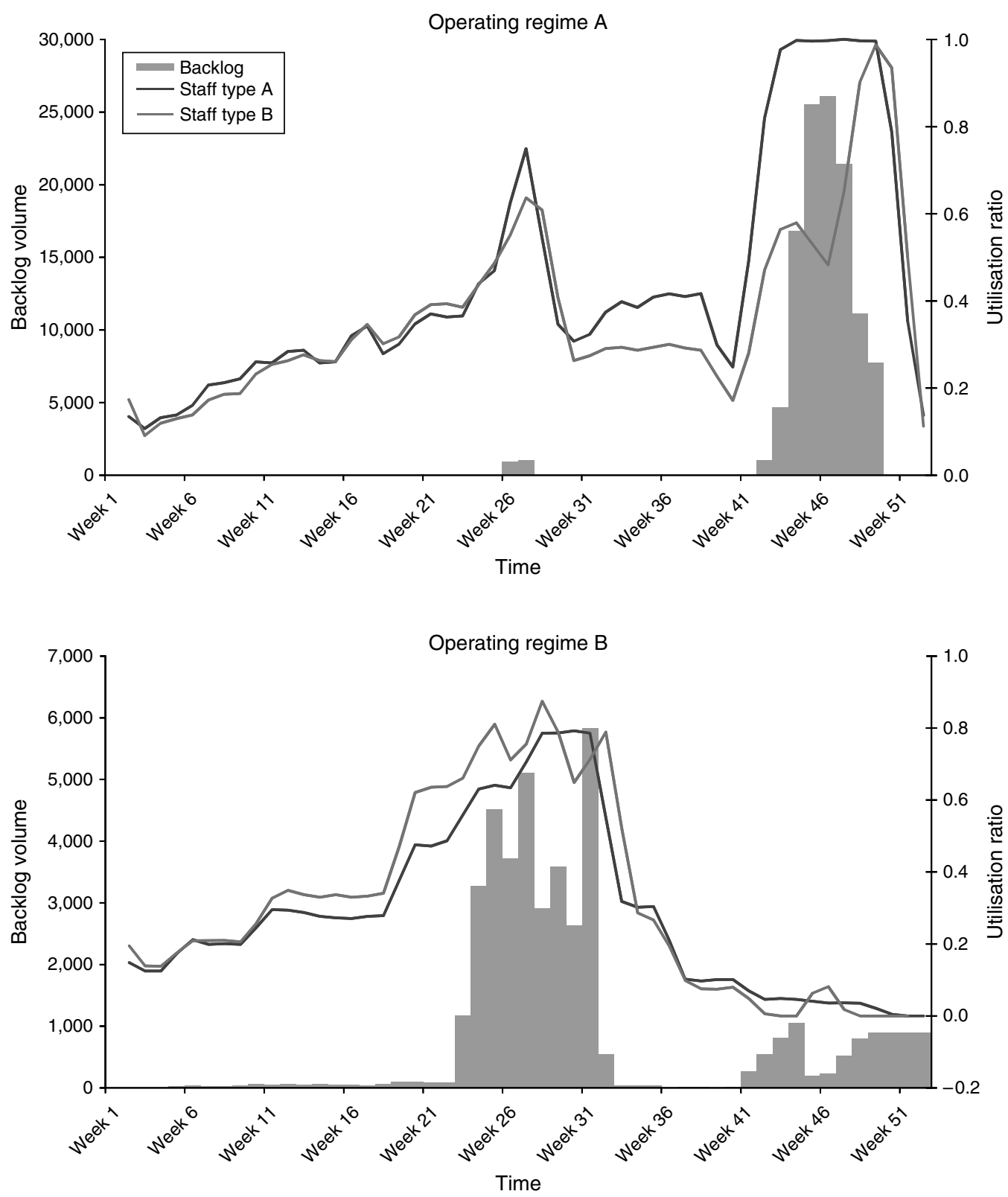

Figure 2: The graphs show simulation output under two operating regimes (with illustrative data).

alternative community settings should be at least cost neutral and potentially cost saving.

To investigate the financial and patient benefits of reduced use of hospital care in the last year of life, the NAO and RAND Europe undertook a joint project to develop a Markov model (Briggs et al. 2006) that would simulate the journey around the health system of an "average" patient with an end-of-life care condition, with author McBride leading from the NAO. The NAO website (http://www.nao.org.uk/ publications/0708/end_of_life_care.aspx) contains full details of the analysis.

Based on the model, the team estimated that in 2006 the cost of care during the year prior to death for 127,000 people in England who died from cancer was $£ 1.8$ billion, and the "average" patient spent 17 
days in hospital. In practice, decreasing reliance on acute care means reducing the number of emergency admissions a cohort experiences. This could be done, for example, by (1) ensuring that community-based options are better positioned to offer the pain relief and other care needed or (2) reducing the length of stay following admission by ensuring that the care program a patient who is discharged into the community requires is put in place in a timely fashion. Thus, the team reduced both the modelled number of emergency admissions the cohort experiences and the average length of stay following an admission. These counterfactual reductions were used to derive new sets of transition probabilities, and the model was rerun to analyse the effect on expenditure and the number of days spent in a hospital during the last year of life. Table 1 displays the resources that would be released.

We then sought expert opinion to identify which of the scenarios tested were the most achievable. We concluded that a 10 percent reduction in the number of admissions experienced by the cohort and a reduction of 3 days (from 11 days to 8 ) in the average length of a hospital stay would be achievable in the medium term. The relevant cell in the table is in italics. This reduction could potentially release approximately $£ 104$ million per year, which could be used to deliver more community-based services and avoid an average of four days in hospital per patient. Data on the costs and practicability of achieving such reductions are limited although the Marie Curie Cancer Care Delivering Choice Programme is encouraging (Addicot and Dewat 2008), because it shows a reduction in hospital admissions and an increase in home

\begin{tabular}{lrrrr}
$\begin{array}{l}\text { Reduction in the } \\
\text { number of emergency } \\
\text { admissions experienced } \\
\text { by the cohort (\%) }\end{array}$ & \multicolumn{4}{c}{$\begin{array}{l}\text { Reduction in average } \\
\text { length of stay per admission }\end{array}$} \\
\cline { 2 - 5 } & 0 days & 1 day & 3 days & 5 days \\
\hline 0 & 0 & 26 & 78 & 132 \\
5 & 16 & 42 & 91 & 141 \\
10 & 33 & 56 & 104 & 151 \\
15 & 49 & 71 & 117 & 161 \\
20 & 66 & 87 & 129 & 171
\end{tabular}

Table 1: The table shows potential resources made available for redistribution through decreased use of hospital care by cancer patients (£ million). deaths with stable overall costs. Thus, a strong case can be made that people's wishes about their place of death can be respected, without increasing taxpayer costs-and possibly reducing these costs (Comptroller and Auditor General 2009a).

\section{Health-Care Associated Infections}

Health-care associated infections (HAIs) are a class of infections acquired after a patient is admitted to a health-care facility, such as a hospital. HAIs result in morbidity and sometimes mortality for the patients, direct financial costs to the system, and concern by the general public.

As part of this study, NAO staff collaborated with a team (authors Lane, Quintas, and Morton) to develop a model relating to one HAI, Clostridium difficile (C. difficile). The team used a system-dynamics modelling approach (Forrester 1961, 1968). The aim was to understand how the underlying mechanisms operate to produce an outbreak in a hospital, and to find potential policy levers to combat such outbreaks.

C. difficile is a bacterium that in harsh environments forms dormant "endospores." The bacterium is found naturally in the gut in approximately 3 percent of the population, but bacterial growth is inhibited by the normal gastrointestinal flora. However, in the general population, growth and infection can occur if spores are ingested, a course of antibiotics has been administered, and individuals have attributes (which are currently poorly understood) that predispose them to develop an infection. In these circumstances, the bacteria release toxins that can lead to illness and even death.

Although the biological characteristics and factors are relatively well known, the relative importance of different mechanisms operating during a hospitalwide outbreak of $C$. difficile and their interactions are not well understood. Improving hygiene, restricting antibiotics usage, increasing single rooms, and lowering bed-occupancy rates are thought to be factors in limiting the spread of $C$. difficile. However, because of the intricate causal relationships between them, the extent to which each is effective is still unknown.

The team constructed a multiplatform, multivector simulation model to help it understand the spread of C. difficile infection throughout a standard-size hospital. The model synthesised data from a variety of 


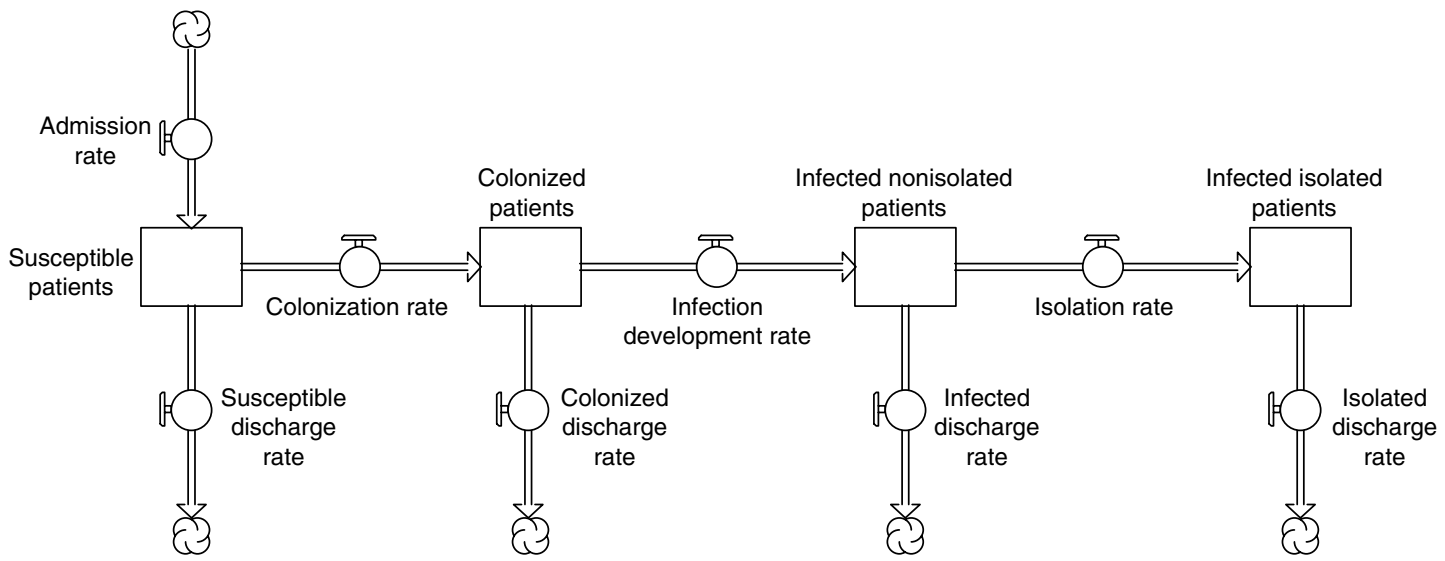

Figure 3: The flowchart shows the process flow for the patients sector in the $C$. difficile model.

sources, including reports on past outbreaks, scholarly literature, and expert opinion. The model used a repeated "SI" structure (Murray 1989) that models how patients transition from a "susceptible" to an "infected" state to capture the movement of spores between four platforms: patients, health-care staff, beds, and patient lavatories. Six transmission vectors were represented: from staff carriers to susceptible patients, then from infectious patients to $C$. difficile-free staff; from contaminated beds to susceptible patients, then from infectious patients to clean beds; from contaminated toilets to susceptible patients, then from infectious patients to cleaned toilets. The model represented patients in different stages of contamination, the processes relating to cleaning beds and toilets, and staff hand cleaning. Figure 3 shows the flow of patients that forms the core of the model, with patients flowing from susceptible to colonized to infected to isolated; Figure 4 shows the transmission mechanisms.

The model parameters can be divided into two broad classes: $C$. difficile biological parameters and hospital-specific management parameters. The first group of parameters is somewhat certain because extensive medical research exists on the $C$. difficile biology, and we conducted an extensive literature review (e.g., Johnson and Gerding 1998, Cooper et al. 1999) and expert interviews to validate these. The second group of parameters are more uncertain and highly hospital specific; we used parameters based on data from the Department of Health that are representative of a midsize UK hospital.
Despite the uncertainty about the parameters, the model runs with all policies turned on do reproduce the behaviour seen in past $C$. difficile outbreaks: a big outbreak followed by a smaller outbreak over the course of three to six months. This gives us confidence that the counterfactual showed by the model (i.e., with no control on) is a plausible account of what would happen in a scenario in which no action is taken. No past data exist for a counterfactual, because a hospital would not let an outbreak run its course without implementing some form of control.

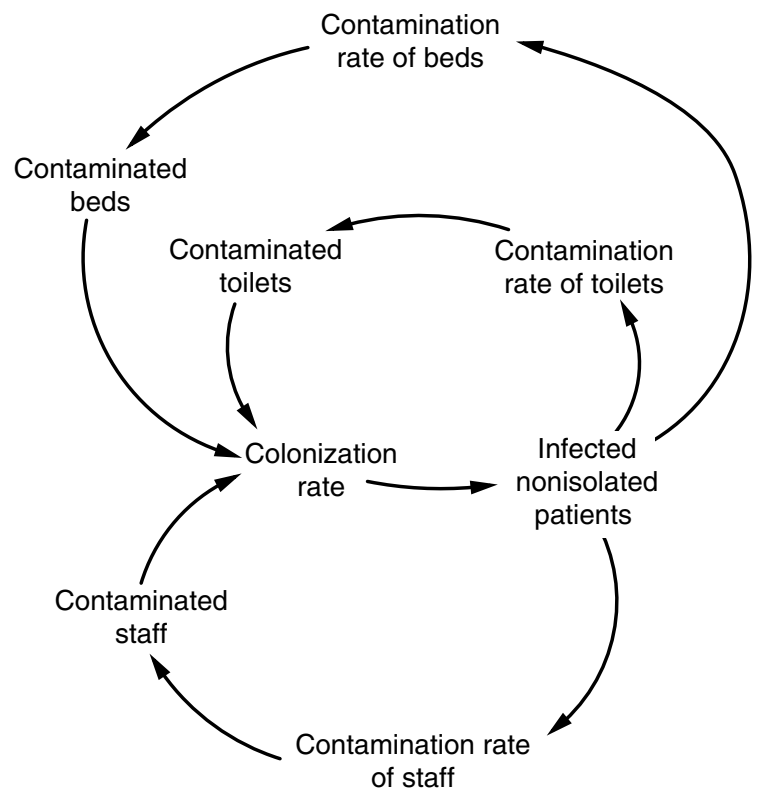

Figure 4: The chart shows a representation of the transmission mechanisms in the $C$. difficile model. 
One use of the model was to explore a scenario in which the first patient brings $C$. difficile into the hospital and an outbreak results. Figure 5 shows the results-how the number of patients falling into various categories changes over time in the course of a model run (the $x$ axis represents time). This is an example of a counterfactual: there is no change in behaviour, no hygiene improvements, and no attempt to isolate patients-none of the actions known to occur in the real world. The purpose of this run is to assist the understanding of the underlying mechanisms of outbreaks. In summary, outbreaks can be seen to be sustained by a combination of new, susceptible patient admissions and the interactions between the six distinct transmission mechanisms.

The contribution of the various policies aimed at combating outbreaks can be judged in proportional terms using spider plots (Eschenbach 1992). The diagram in Figure 6 shows the reduction in the fractional number of infected patients relative to a baseline run when parameters representing policy levers are varied. Clearly, improvements to bed, toilet, and hand cleaning have little effect when implemented individually, because the feedback loops created by the other transmission vectors "take up the slack." Only combinations of all three can be effective. Equally clearly from the figure, a reduction in antibiotics prescriptions is a significant factor in combating outbreaks: in this respect, the model is consistent with previous and current recommendations to hospitals.

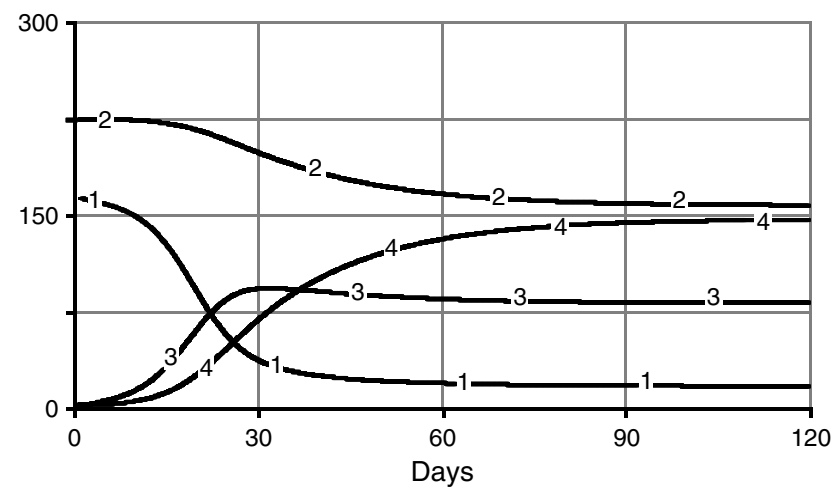

Figure 5: The graph illustrates the model simulation for the "outbreak only" scenario, showing the dynamics for the main categories of patients in a C. difficile outbreak. Notes. 1: susceptible patients; 2: nonsusceptible patients; 3: colonized patients; 4 : total infected patients.

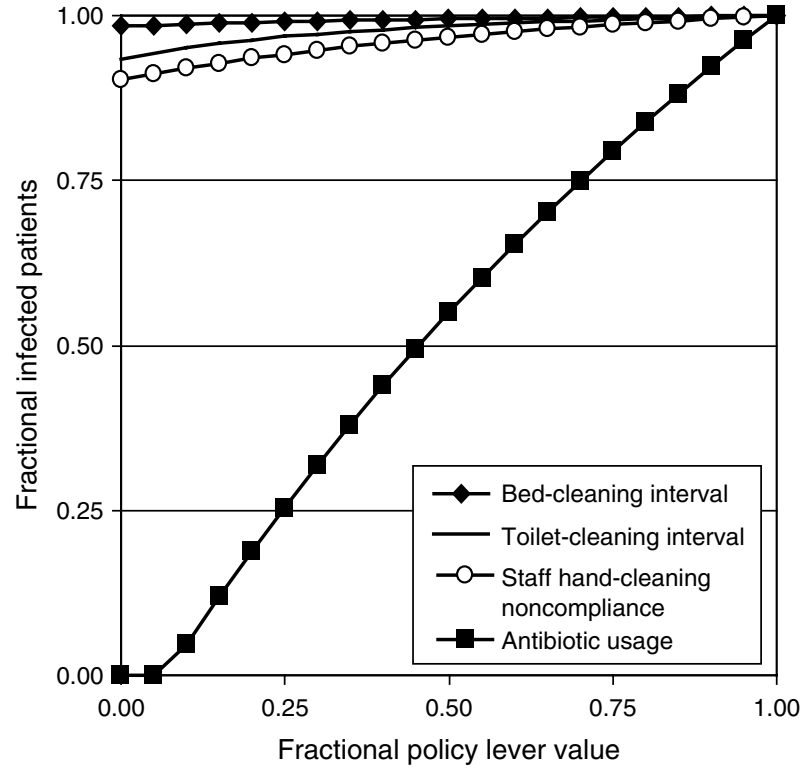

Figure 6: A spider plot shows the effects of the fractional reduction in the steady-state number of infected patients caused by changes to a range of policy parameters in the model.

An important insight we observed from running this model was that detecting and isolating patients with $C$. difficile is effective in combating an outbreak. The model allows the exploration of the trade-offs between capacity and the delay before isolation takes place: lower isolation capacity can be compensated for by lower delay. This last point was particularly important because one finding from the empirical part of the study was that 89 percent of infection-control teams felt that bed managers were seeking and following their advice before making decisions about patient isolation, compared to 46 percent in 2004. Thus, although a perceived shortage of isolation facilities still exists, hospitals are generally making substantially better use of these facilities (Comptroller and Auditor General 2009e).

\section{Conclusion}

Convincing SAI staff about the benefits of modelling methods can be difficult. SAI staff members typically have strong quantitative backgrounds but tend to be accounting trained rather than OR trained, although the professional background of VFM auditors in the NAO has become increasingly more diverse in the past decade. Moreover, many auditors fear that their 
audit clients or primary customers (Members of Parliament in the case of the NAO) may balk at the use of apparently arcane methods. Both these clients and the audited departments are often unsure to what extent they can rely on findings based on "assumptions" and "abstractions of reality." Another pragmatic concern is that the time frame of the typical audit study is too short for the use of modelling and the report, typically about 10,000 words, does not allow for detailed technical work.

Although such concerns have some validity, they can be overdone. Clients and customers are interested in strong and robust conclusions, and have a right to expect that these conclusions are based on the best methods available; technical material can be relegated to a technical annex or supplementary report, and even simple models can be insightful and useful. The modelling experiences reported above show the diverse areas of application of OR and the range of ways in which modelling can be used: to force study teams to ask basic questions and drive dialogue about work processes and measurements with audited departments (i.e., HMRC); to structure interaction with subject-matter experts and provide a framework for the elicitation of expert judgment (i.e., end-of-life); and to capture, synthesise, and record information from a wide range of sources (i.e., HAI). In all cases, the models feature in the VFM report (Comptroller and Auditor General 2009a, b, e), and the study team felt they were helpful in coming to a judgment about value for money.

Overall, the experiences reported here show that OR models can be a valuable addition to the auditor's toolbox, providing new insight into problems under investigation. When used appropriately and integrated within a study that utilises a range of other methodologies, models allow the examination of counterfactuals and are a basis for quantifying the outcomes of recommendations. The NAO continues to explore the use of the models, and recent studiesfor example, on stroke care and the processing of telephone tax inquiries-have used models (Comptroller and Auditor General 2010a, b). Although the application of such models has so far largely been concentrated in the areas of health and taxation, exploration of wider use in other policy areas is being undertaken. Moreover, the NAO has recently developed and run a modelling training programme, has hired a number of operations researchers to develop its competency in this area, and has set up an internal modelling expert group. Therefore, we consider that the relevance of OR modelling to value-for-money audit has been effectively demonstrated.

\section{Acknowledgments}

Alec Morton is grateful to the Economic and Social Research Council who partly funded his secondment to the NAO as a visiting senior fellow in the first half of 2008 under grant RES-173-27-0036. The authors are also grateful to Andy Fisher, Nick Lacy, Jeremy Lonsdale, Andrew Morrison, Andy Nichols, Will Palmer, Alex Scharaschkin, David Sewell, Karen Taylor, Anna Ward, and Jane Wheeler from $\mathrm{NAO}$, and many other unnamed NAO staff members for their support of the work described here, and for helpful discussions during the preparation of this paper. They also express thanks to Fragiskos Archontakis, Andrew Daly, Evi Hatziandreu, and Christian van Stolk from RAND Europe, with whom they worked on the end-of-life study, and to staff from the Health Protection Agency and King's College Hospital who shared their expertise on the HAI study. In all cases, any errors are the responsibility of the authors.

\section{References}

Addicot, R., S. Dewat. 2008. Improving choice at the end of life. A Descriptive Analysis of the Marie Curie Delivering Choice Programme in Lincolnshire. King's Fund, London.

Banks, J., J. S. Carson, N. L. Nelson, D. M. Nicol. 2000. DiscreteEvent System Simulation. Prentice Hall, Englewood Cliffs, NJ.

Barzelay, M. 1997. Central audit institutions and performance auditing: A comparative analysis of organizational strategies in the OECD. Governance Internat. J. Policy Admin. 10(3) 235-260.

Briggs, A., K. Claxton, M. Sculpher. 2006. Decision Modelling for Health Economic Evaluation. Oxford University Press, Oxford, UK.

Comptroller and Auditor General. 2004. The recovery of debt by the inland revenue. Report HC 363 2003-2004, National Audit Office, London.

Comptroller and Auditor General. 2006. Helping newly registered businesses meet their tax obligations. Report HC 98 2006-2007, National Audit Office, London.

Comptroller and Auditor General. 2008. Mathematics performance in primary schools: Getting the best results. Report HC 1151 2007-2008, National Audit Office, London.

Comptroller and Auditor General. 2009a. End of life care. Report HC 1043 2007-2008, National Audit Office, London.

Comptroller and Auditor General. 2009b. HM Revenue and Customs: Managing variations in workload. Report HC 507 20082009, National Audit Office, London.

Comptroller and Auditor General. 2009c. The nationalisation of Northern Rock. Report HC 298 2008-2009, National Audit Office, London.

Comptroller and Auditor General. 2009d. Providing anti air warfare capability: The type 45 destroyer. Report HC 295 2008-2009, National Audit Office, London. 
Comptroller and Auditor General. 2009e. Reducing healthcare associated infections in hospitals in England. Report HC 560 2008-2009, National Audit Office, London.

Comptroller and Auditor General. 2010a. Department of Health: Progress in improving stroke care. Report, HC 291 2009-2010, National Audit Office, London.

Comptroller and Auditor General. 2010b. HM Revenue and Customs: Handling telephone enquiries. Report HC 211 2009-2010, National Audit Office, London.

Cooper, B. S., G. F. Medley, G. M. Scott. 1999. Preliminary analysis of the transmission dynamics of nosocomial infections: Stochastic and management effects. J. Hospital Infection 43(2) 131-147.

Eschenbach, T. G. 1992. Spiderplots versus tornado diagrams for sensitivity analysis. Interfaces 22(6) 40-46.

Forrester, J. W. 1961. Industrial Dynamics. MIT Press, Cambridge, MA.

Forrester, J. W. 1968. Principles of Systems. MIT Press, Cambridge, MA.

Johnson, S., D. N. Gerding. 1998. State-of-the-art clinical article: Clostridium difficile-Associated diarrhea. Clinical Infectious Diseases 26(5) 1027-1036.

Law, A. M., W. D. Kelton. 2000. Simulation Modelling and Analysis. McGraw-Hill, Boston.

Ling, T. 2007. New wine in old bottles? When audit, accountability and evaluation meet. M.-L. Bemelmans-Videc, B. Perrin, J. Lonsdale, eds. Making Accountability Work: Dilemmas for Evaluation and for Audit. Transaction Publishers, Piscataway, NJ.

Murray, J. D. 1989. Mathematical Biology. Springer, Berlin.

Pidd, M. 2004. Computer Simulation in Management Science. Wiley, Chichester, UK.

Pollitt, C., X. Girre, J. Lonsdale, R. Mul, H. Summa, M. Waerness. 1999. Performance or Compliance? Performance Audit and Public Management in Five Countries. Oxford University Press, Oxford, UK.

Jeremy Lonsdale, Director-General, Performance Audit, National Audit Office, 157-197 Buckingham Palace Road, Victoria, London SW1W 9SP, United Kingdom, writes: "I am writing to verify that the OR modelling techniques have been used as described in the paper 'The National Audit Office Uses OR to Assess the Value for Money of Public Services' by Elena Bechberger, David C. Lane, Tom McBride, Alec Morton, Diogo Quintas, and Chin Hei Wong and that they have been very valuable in helping us to expand the range of techniques that we employ in reaching our VFM conclusions.

"The paper is based on three recent case study examples, drawn from a number of areas of NAO's work, where OR modelling techniques have been used. The first is our study of end of life care for terminally ill people. As part of this study, we worked with RAND Europe to develop a Markov model. This runs 365 cycles for a cohort of patients, each cycle representing a day. Each day, a patient can be in one of three settings-at home, in the community or in hospital. We used the model to identify the potential savings that could be made from different scenarios, and concluded that a $10 \%$ reduction in hospital admissions and a 3day reduction in hospital stays would release $£ 104$ million to deliver improved community services.

"The second case study examined demand management at HM Revenue and Customs. HMRC experiences huge variations in workload with peaks and troughs dictated by the deadlines for submission of self-assessment tax returns. The peaks result in a high level of overtime, reduced staff performance, backlogs and inefficient use of resources. We used a Discrete Event Simulation Model to simulate the resource utilisation at different stages of the self-assessment cycle and provide practical advice to the Department on more efficient deployment of resources, stockpiling of self-assessment forms and shifting of deadlines. The model demonstrated how a more even workload and a significant backlog reduction could be achieved.

"In the final example, we used a system dynamics modelling approach to provide understanding of the underlying mechanisms that operate during an outbreak of hospital associated infections. The model synthesised data from a variety of sources including reports on past outbreaks, literature review and expert opinion. The model captured the movement of spores between four platforms-patients, staff, beds, and patient toilets-to simulate an outbreak, and enabled an evaluation of how effective different activities such as bed, toilet, and hand cleaning, reductions in antibiotic prescriptions and patient detection and isolation are in reducing the spread of infections. The model has made a significant contribution to the debate on how best to reduce the incidence of healthcare associated infections.

"Together, these models have in all cases provided insights and learning which have been used in NAO reports to help underpin conclusions on value for money. The models themselves have been cited in the reports in support of audit conclusions, and these reports have been used by Parliament to hold government to account. These experiences have demonstrated the value of Operations Research to the NAO and the Office is currently looking to encourage the use of modelling across the range of its work by employing OR experts and providing a range of training courses and seminars. In conclusion, I am pleased to endorse the value of this work, and note that we will be continuing to explore how we can use such techniques in our VFM audit work." 